\title{
ASSESSMENT OF GROUP A STREPTOCOCCUS AND ANTIMICROBIAL RESISTANCE PATTERN IN SCHOOL GOING CHILDREN IN MORANG DISTRICT, NEPAL
}

\author{
Chaudhary $K K^{1^{*}}$, Khanal $H^{1}$, Singh $K G^{1}$, Chaudhary $S R^{2}$, Sah $O P^{3}$
}

\section{Affiliation}

1. Lecturer, Mahendra Morang Adarsh Bahumukhi Campus, Biratnagar, Morang, Nepal

2. Lecturer, Sunsari Technical College, Bhupi Marg, Dharan,Nepal

3. Lecturer, Noble Medical College Teaching Hospital, Kanchanbari-5, Biratnagar, Morang, Nepal

4. Lecturer, Birat Medical College Teaching Hospital, Budhiganga, Tankisinwari, Morang, Nepal

5. Dietitian and Nutritionist, Birat Medical College Teaching Hospital, Budhiganga, Morang, Nepal

\section{ARTICLE INFO}

Received : 22 February, 2020

Accepted : 19 November, 2020

Published : 22 December, 2020

(c) Authors retain copyright and grant the journal right of first publication with the work simultaneously licensed under Creative Commons Attribution License CC - BY 4.0 that allows others to share the work with an acknowledgment of the work's authorship and initial publication in this journal.

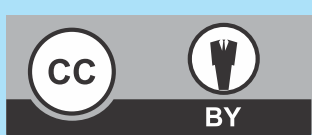

ORA 197

DOI: https://doi.org/10.3126/bjhs.v5i3.33684

* Corresponding Author

Ms. Kabita Kumari Chaudhary Lecturer

Mahendra Morang Adarsh Bahumukhi Campus Biratnagar, Morang, Nepal

Email ID: kavita22biratnagar@gmail.com ORCID ID: https://orcid.org/0000-0000-0002-2091-6572

\section{Citation}

Chaudhary KK, Khanal H, Singh KG, Chaudhary SR, Sah OP. Assessment of group a Streptococcus and Antimicrobial Resistance Pattern in School Going Children in Morang District, Nepal BJHS 2020;5(3)13.1148-1154.

\section{ABSTRACT}

Introduction

Group A $\beta$-hemolytic Streptococcal infections are common among children, possesses significant problem globally, especially affecting developing countries with lacking baseline information.

\section{Objective}

To assess prevalence of Group A $\beta$-hemolytic Streptococcus and its antimicrobial resistance pattern in school aged children of Morang, Nepal.

\section{Methodology}

This was a 9 months long community based cross-sectional study. A total of 518 children (both symptomatic, asymptomatic) from different schools were enrolled. Swabs were collected from the tonsils and posterior pharyngeal wall and were subjected to microbial analysis. The specimens were inoculated into Blood agar and MacConkey agar and were incubated at $37^{\circ} \mathrm{C}$ aerobically and checked for growth after overnight incubation. The identification of bacterial isolates was done using CLSI guidelines. Biochemical tests like catalase, bacitracin sensitivity test (0.004 units), Lancefield grouping (Pastorex ${ }^{\mathrm{TM}}$ Strep) were performed. All the identified $S$. pyogenes isolates thus obtained were subjected to in vitro antibiotics sensitivity testing by using Kirby-Bauer disc- diffusion method as per CLSI(2014).

\section{Result}

Throat swabs were collected from a total of 518 (303 male and 215 female) school aged children only after after taking verbal and written consent. Group A streptococci (GAS) was isolated from $28(5.4 \%)$, of which $15(5 \%)$ were male and 13 (7\%) were female, without significant sex difference with majority being asymptomatic. It was observed that GAS were sensitive to Penicillin and their derivatives (100\%), Ciprofloxacin (100\%) and Azithromycin (100\%) followed by Erythromycin (75\%) and Cotrimoxazole (71.4\%)

\section{Conclusion}

This study provides the base-line information on the GAS carriage rate and resistance trend among school aged children. It also showed that Penicillin and its derivatives should be used to treat a case of GAS pharyngitis. S. aureus is apparently one of the causative agents of pharyngitis and hence throat swab culture should be requested for appropriate therapy.

\section{KEYWORDS}

Anti-Infective agents, pharyngitis, staphylococcus, streptococcus 


\section{INTRODUCTION}

Group A streptococci (GAS) can cause a wide range of infections, which can lead to pharyngitis, scarlet fever, impetigo or cellulites etc. People that come in contact with GAS may develop invasive Group A streptococcal disease. The person suffering from chronic illness like cancer, diabetes, and chronic heart and lung disease, those who use medications such as steroids and the children living in a crowded area are prone to develop disease.

In Nepal prevalence rate according to school survey occur 5-7 per 100 children (Incidence and Prevalence). GAS is the most frequently isolated pathogen in acute pharyngitis among school-going children. ${ }^{1}$ If streptococcal infection is left untreated, it may give rise to rheumatic fever, rheumatic heart disease and less often glomerulonephritis as a sequelae. ${ }^{2}$ Pharyngo-tonsillitis caused by beta haemolytic streptococci remains an epidemic disease with annual incidence ranging from 1-2\% school-going children and is a major cause of cardiovascular mortality. ${ }^{3}$ Rheumatic fever is reported to occur in 1-3\% of streptococcal throat infections of children living in under privileged condition. ${ }^{3,4}$

The prevalence of congenital heart disease (CHD) and rheumatic heart disease (RHD) in school going children has been rarely studied in Nepal. Studies done in different parts of our country in the last two decades, have shown prevalence of RHD to vary from 1.2 to 1.35 per thousand school aged children and prevalence of CHD to be 1.3 per thousand. ${ }^{5,6}$

The incidence of sore throat infection in developing countries appears to be 200 per 1000 children and the prevalence rates according to community and school survey range from 1 to 44 per 1000 .

The aim of this study was to report the findings of sore throat infections among school going children of Morang District Nepal. This study focused on school-going children of urban as well as rural population of Morang District Nepal and aimed to see the trend of the disease compared to findings from prior studies which were done in the last two decades in Nepal.

\section{METHODOLOGY}

\section{Laboratory Setting}

This study was community based cross-sectional study conducted at Department of Microbiology, Noble Medical College, Biratnagar in joint collaboration with Sunsari Technical College, Dharan between July 2015 to March 2016 (over a period of 9 months). During the study, a total of 518 patients (school-going children) from different school who were symptomatic as well as asymptomatic, were enrolled.

\section{Laboratory Investigation:}

All samples were collected by rubbing quickly and thoroughly over either tonsils (or tonsillar fossa) and over the posterior wall of the pharynx using light pressure and were subjected to microbial analysis in the clinical Microbiology Laboratory of Noble Medical College. Swabbing was done under direct vision and with the aid of a tongue depressor and samples was collected aseptically. The specimens were inoculated immediately into Blood agar
(BA) and MacConkey agar (MA) and were incubated at $37^{\circ} \mathrm{C}$ aerobically and were checked for growth after overnight incubation. The identification of bacterial isolates was carried out by CLSI guidelines with colonial morphology and staining reactions. Appropriate biochemical tests were performed for the final identification of bacterial isolate. Each organism was grown in its pure form for biochemical and other tests. Gram's staining were performed from primary cultures. Biochemical tests such as catalase, bacitracin sensitivity test (0.004 units) and Lancefield grouping (Pastorex ${ }^{\mathrm{TM}}$ Strep) were performed.

\section{Antibiotic susceptibility testing:}

All the identified S. pyogenes isolates thus obtained were subjected to in vitro antibiotics sensitivity testing by using Kirby-Bauer disc- diffusion method as recommended by CLSI (2014).

\section{RESULTS}

A total of six schools were randomly selected for study purpose. Four schools (A, B, C \& D) were owned by private sector while two ( $E$ \& F) were owned by Government of Nepal. The highest number of male and female were from school A (i.e. $60 \%$ and $39 \%$ ) while lowest number of male and female (i.e. $56 \%$ and $44 \%$ ) were from school $\mathrm{F}$.

\begin{tabular}{cccc}
\multicolumn{4}{c}{ Table 1: Distribution of study population by school and gender } \\
\hline \multicolumn{4}{c}{ Gender } \\
\hline School & Male & Female & Total \\
\hline A & $99(60 \%)$ & $64(40 \%)$ & $163(100 \%)$ \\
B & $59(63 \%)$ & $34(37 \%)$ & $93(100 \%)$ \\
C & $16(62 \%)$ & $10(38 \%)$ & $26(100 \%)$ \\
D & $72(55 \%)$ & $57(45 \%)$ & $129(100 \%)$ \\
E & $48(52 \%)$ & $43(48 \%)$ & $91(100 \%)$ \\
F & $09(56 \%)$ & $07(44 \%)$ & $16(100 \%)$ \\
\hline Total & $303(58 \%)$ & $215(42 \%)$ & $518(100 \%)$
\end{tabular}

Out of total 518 samples, 28 (6\%) showed growth of S. pyogenes. The highest number of growth of $S$. pyogenes were found in school $F(13 \%)$. Similarly, $5 \%$ in school A, 3\% in school B, 4\% in school C and 6\% in school D and $E$ and $13 \%$ in school F. There were no statistically significant correlations between school wise distributions of population according to positivity of Streptococcus ( $p$-value=0.288).

Table 2: School-wise distribution of population according to positivity of Streptococcus

\begin{tabular}{lccll}
\multirow{2}{*}{ School } & \multicolumn{2}{c}{ S. pyogenes } & \multirow{2}{*}{ Total } & $p$-value \\
\cline { 2 - 3 } & No growth & Growth & & \\
\hline A & $155(95 \%)$ & $08(5 \%)$ & $163(100 \%)$ & \\
B & $90(97 \%)$ & $03(3 \%)$ & $93(100 \%)$ & \\
C & $25(96 \%)$ & $01(4 \%)$ & $26(100 \%)$ & 0.288 \\
D & $121(94 \%)$ & $08(6 \%)$ & $129(100 \%)$ & \\
E & $85(94 \%)$ & $06(6 \%)$ & $91(100 \%)$ & \\
F & $14(87 \%)$ & $02(13 \%)$ & $16(100 \%)$ & \\
\hline Total & $490(94 \%)$ & $28(6 \%)$ & $518(100 \%)$ & \\
\hline
\end{tabular}


Total 48 isolates were found to be Staphylococcus aureus. Among them $10 \%$ were isolated from school $A, 4 \%$ from school B, 11\% from school C, $9 \%$ from school D, 14\% from school $E$ and $6 \%$ from school $F$ respectively. There were no statistically significant correlations between school wise distributions of population according to positivity of Staphylococcus ( $p$-value $=0.249$ ).

Table 3: School-wise distribution of population according to positivity of Staphylococcus

\begin{tabular}{ccccc}
\multirow{2}{*}{ School } & \multicolumn{2}{c}{ Staphylococcus } & \multirow{2}{*}{ Total } & $p$. value \\
\cline { 2 - 4 } & No growth & Growth & & \\
A & $147(90 \%)$ & $16(10 \%)$ & $163(100 \%)$ & \\
B & $89(96 \%)$ & $04(4 \%)$ & $93(100 \%)$ & \\
C & $23(89 \%)$ & $03(11 \%)$ & $26(100 \%)$ & 0.249 \\
D & $117(91 \%)$ & $12(9 \%)$ & $129(100 \%)$ & \\
E & $79(86 \%)$ & $12(14 \%)$ & $91(100 \%)$ & \\
F & $15(94 \%)$ & $01(6 \%)$ & $16(100 \%)$ & \\
Total & $470(90 \%)$ & $48(10 \%)$ & $518(100 \%)$ &
\end{tabular}

Among the randomly selected study population highest number of study population was found to be Janjati ethnic group (254) whereas lowest number was from Dalit ethnic group. The highest number of study populations belonged to age group (13-14 years) while lowest was from age group 5-6 years. Remaining others were 135 from $11-12$ years age group, 108 from 15 years age group, 73 from 9-10 years age group, 18 from 7-8 years age group. There were no statistically significant correlations between ethnic and age wise distribution of study population ( $p$-value $=0.242$ ).

\begin{tabular}{|c|c|c|c|c|c|c|}
\hline \multirow{2}{*}{$\begin{array}{l}\text { Age } \\
\text { Range }\end{array}$} & \multicolumn{4}{|c|}{ Ethnic Group } & \multirow{2}{*}{ Total } & \multirow{2}{*}{$\begin{array}{c}p \text { - } \\
\text { value }\end{array}$} \\
\hline & Madeshi & Janjati & Brahmins & Dalit & & \\
\hline 5-6 & - & $03(3 \%)$ & - & - & $03(3 \%)$ & \\
\hline $7-8$ & - & $11(62 \%)$ & $04(23 \%)$ & 03 (15\%) & $18(100 \%)$ & \\
\hline $9-10$ & $06(9 \%)$ & $34(46 \%)$ & $23(31 \%)$ & $10(14 \%)$ & 73 (100\%) & \\
\hline $11-12$ & $20(15 \%)$ & $65(48 \%)$ & 47 (35\%) & $03(2 \%)$ & 135 (100\%) & 0.242 \\
\hline $13-14$ & $34(18 \%)$ & 90 (49\%) & $54(30 \%)$ & $03(3 \%)$ & $181(100 \%)$ & \\
\hline 15 & 06 (5\%) & $51(47 \%)$ & $51(48 \%)$ & - & $108(100 \%)$ & \\
\hline Total & $66(13 \%)$ & $254(49 \%)$ & $179(34 \%)$ & $19(4 \%)$ & $518(100 \%)$ & \\
\hline
\end{tabular}

Out of 411 samples collected from private sector school, 20 samples yielded growth of S. pyogenes \& 35 yielded growths of S. aureus. Similarly out of 107 samples collected from government owned school 7 were culture positive for Streptococcus pyogenes and 12 for Staphylococcus aureus. There were no statistically significant correlations between distribution of positive isolates in private and government schools ( $p$-value $=0.223$ ).
Table 5: Distribution of positive isolates in private and government schools

\begin{tabular}{|c|c|c|c|c|}
\hline \multirow{2}{*}{ Organism } & \multicolumn{2}{|c|}{ School Type } & \multirow{2}{*}{ Total } & \multirow{2}{*}{$p$-value } \\
\hline & Private & Government & & \\
\hline Streptococcus & 20 & 07 & 27 & \multirow{5}{*}{0.223} \\
\hline Staphylcoccus & 35 & 12 & 47 & \\
\hline $\begin{array}{l}\text { Streptococcus \& } \\
\text { Staphylcoccus }\end{array}$ & - & 01 & 01 & \\
\hline No Growth & 356 & 87 & 443 & \\
\hline Total & 411 & 107 & 518 & \\
\hline
\end{tabular}

Among the isolates of Staphylococcus aureus, 13\% were isolated from students of age group 11-12 and age group 15, $7 \%$ from age group $13-14,5 \%$ from age group $9-10$ and $7-8$. There were statistically significant between the distribution of positive isolates of Staphylococcus according to age group of study population $(p=0.05)$. Unlike Staphylococcus, highest numbers of Streptococcus were isolated from student of age group 13-14 years and lowest from age group 7-8 years. No growth was observed in 5-6 years age group of students. There were statistically significant correlations between distribution of positive isolates of Streptococcus according to age group of study population ( $p$-value $=0.05$ ).

\begin{tabular}{|c|c|c|c|c|c|c|}
\hline \multirow{2}{*}{$\begin{array}{l}\text { Age } \\
\text { Range }\end{array}$} & \multicolumn{4}{|c|}{ Organism } & \multirow{2}{*}{ Total } & \multirow{2}{*}{$\begin{array}{c}p- \\
\text { value }\end{array}$} \\
\hline & S. pyogenes & S. aureus & $\begin{array}{l}\text { S. pyogenes + } \\
\text { S. aureus }\end{array}$ & No Growth & & \\
\hline $5-6$ & - & - & - & $03(3 \%)$ & $03(3 \%)$ & \\
\hline $7-8$ & $01(5 \%)$ & $01(5 \%)$ & - & $16(90 \%)$ & $18(100 \%)$ & \\
\hline $9-10$ & $02(3 \%)$ & $03(5 \%)$ & - & 68 (92\%) & $73(100 \%)$ & 0.05 \\
\hline $11-12$ & $06(5 \%)$ & 17 (13\%) & $01(1 \%)$ & $111(81 \%)$ & 135 (100\%) & \\
\hline $13-14$ & $10(5 \%)$ & $12(7 \%)$ & - & $159(88 \%)$ & $181(100 \%)$ & \\
\hline $\begin{array}{l}\text { Above } \\
15\end{array}$ & $08(7 \%)$ & $14(13 \%)$ & - & $86(80 \%)$ & $108(100 \%)$ & \\
\hline Total & $27(6 \%)$ & $47(10 \%)$ & 01 (1\%) & 443 (84\%) & $518(100 \%)$ & \\
\hline
\end{tabular}

Among 487 asymptomatic cases $S$. pyogenes were isolated from $16(4 \%)$ students. Out of 31 symptomatic cases 12 (39\%) were positive for S. pyogenes. There were statistically significant correlations between symptomatic distributions of population according to Streptococcal isolates $(p$-value=0.01).

\begin{tabular}{|c|c|c|c|c|}
\hline \multirow{2}{*}{ Symptoms } & \multicolumn{2}{|c|}{ Streptococcus pyogenes } & \multirow{2}{*}{ Total } & \multirow{2}{*}{$p$-value } \\
\hline & No Growth & Growth & & \\
\hline Asymptomatic & $471(96 \%)$ & $16(4 \%)$ & 487 (100\%) & \multirow{3}{*}{0.01} \\
\hline Symptomatic & $19(61 \%)$ & $12(39 \%)$ & $31(100 \%)$ & \\
\hline Total & $490(94 \%)$ & $28(6 \%)$ & $518(100 \%)$ & \\
\hline
\end{tabular}

Among 487 asymptomatic cases $S$. aureus were isolated from $39(81 \%)$ students. Out of 31 symptomatic cases 9 (19\%) were positive for S. aureus. There were statistically significant correlations between symptomatic distributions Staphylococcal isolates ( $p$-value=0.01). 


\begin{tabular}{|c|c|c|c|c|}
\hline \multirow{2}{*}{ Staphylococcus } & \multicolumn{2}{|c|}{ Symptoms } & \multirow{2}{*}{ ic Total } & \multirow{2}{*}{$p$-value } \\
\hline & Asymptomatic & Symptomatic & & \\
\hline No Growth & 448 (95\%) & $22(5 \%)$ & 470 (100\%) & \multirow{3}{*}{0.01} \\
\hline Growth & 39 (81\%) & 09 (19\%) & $48(100 \%)$ & \\
\hline Total & 487 (94\%) & $31(6 \%)$ & 518 (100\%) & \\
\hline
\end{tabular}

Among 215 female students, 7\% were colonized with $S$. pyogenes and out of 303 male students, $5 \%$ were colonized with S. pyogenes.

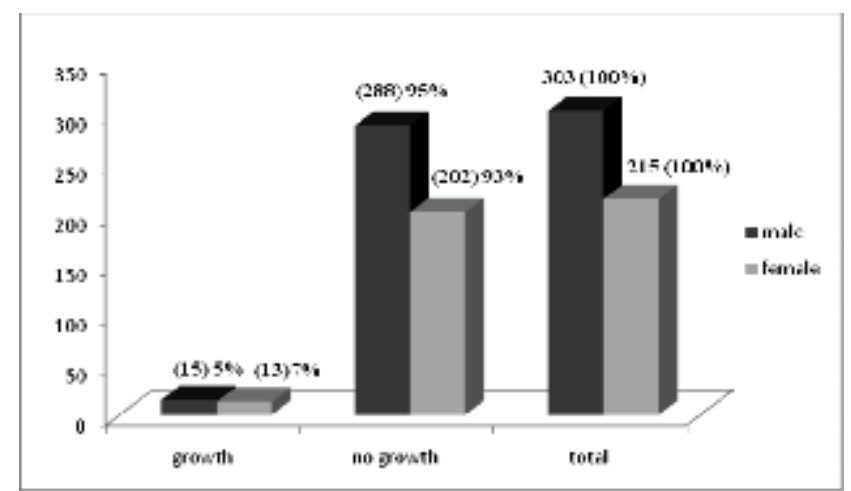

Figure 1: Distribution of Streptococcus among different gender population

Out of 215 female students and 303 male students S. aureus was isolated from $10 \% \& 7 \%$ respectively

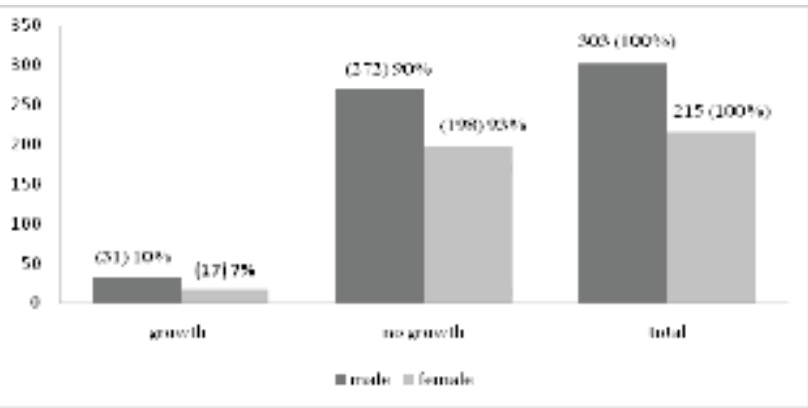

Figure 2: Distribution of Staphylococcus among different Gender population

Table 9: Antibiotic susceptibility pattern of $\beta$-hemolytic streptococci isolates

\begin{tabular}{|c|c|c|c|c|c|c|}
\hline \multirow[t]{2}{*}{ Antibiotics } & \multicolumn{2}{|c|}{ Sensitive } & \multicolumn{2}{|c|}{$\begin{array}{c}\text { Patten } \\
\text { Intermediate } \\
\end{array}$} & \multicolumn{2}{|c|}{ Resistant } \\
\hline & N & $\%$ & N & $\%$ & $\mathbf{N}$ & $\%$ \\
\hline Azithromycin & 28 & 100 & - & - & - & - \\
\hline Ciprofloxacin & 28 & 100 & - & - & - & - \\
\hline Co-trimoxazole & 20 & 71.4 & 02 & 7.1 & 06 & 21.5 \\
\hline Erythromycin & 21 & 75 & - & - & 07 & 25 \\
\hline Penicillin & 28 & 100 & - & - & - & - \\
\hline
\end{tabular}

The antibiotic susceptible pattern of Staphylococcus aureus shows $100 \%$ sensitive to Amikacin, Linezolid, Teicoplanin and Vancomycin. Similarly, it was found that $98 \%$ sensitive to Chloramphenicol, $60 \%$ sensitive to Clindamycin, $47 \%$ to Cotrimoxazole, followed by $68 \%$ sensitive to Cloxacillin, $70 \%$ sensitive to Erythromycin and $29 \%$ sensitive to Penicillin respectively.

\begin{tabular}{l} 
Table 10: Antibiotic susceptibility pattern of Staphylococcus \\
isolates \\
\cline { 2 - 7 } Antibiotics
\end{tabular}

\section{DISCUSSION}

The Group A streptococcal pharyngitis is a common infectious disease with a well-recognized clinical pattern, as opposed to that attributed to group C assault. Group A streptococcal pharyngitis is more common during the winter and rainy months and occurs most frequently in school going children. Typically, the patient is between 5 to 15 years of age, with a sudden onset of high fever and sore throat. The GAS (Streptococcus pyogenes) has remained a significant human pathogen for centuries. Streptococcal infections and their complications have been carefully studied, yet diagnostic and therapeutic dilemmas concerning their management remains. This organism causes a wide variety of infections in humans, ranging from mild upper respiratory and skin infections, to severe supportive and invasive conditions like necrotizing fasciitis and toxic shock syndrome. Of major concern is that post infectious sequel like acute rheumatic fever and post-streptococcal glomerulonephritis continue to occur worldwide despite efforts by clinicians, scientists and public health officials to comprehend their pathogenesis and devise ways of disease control.

It is estimated that Bangladesh, Bhutan, India, Indonesia, Myanmar and Nepal together account for $40 \%$ of the global acute respiratory infection (ARI). ${ }^{8}$ The incidence of upper respiratory tract infections in developing countries has been difficult to determine accurately. ${ }^{9}$ It is estimated that GAS pharyngitis has over 616 million incident cases per year in the world. ${ }^{10}$

The present study was conducted in Nobel medical college, Biratnagar from July 2015 to March 2016. A total of 518 clinical samples were collected from school going children. The samples were delivered to the clinical laboratory of Nobel medical college and were processed according to the standard microbiological methods for culture. All culture positive samples were further processed for antibiotic susceptibility test by modified Kirby Baur disc diffusion method.

Bacitracin disc (10 units) was used for preliminary detection of S. pyogenes. Presence of any zone of inhibition around discs was considered positive for Lancefield Group A streptococci. 
Out of the total clinical sample processed, 28 samples revealed growth of $S$. pyogenes (Table 2 ) and 48 showed growth of Staphylococcus aureus (Table 3). The percentage of GAS (Figure 1) as well as $S$. aureus isolates (Figure 2 ) was found high in male as compared to female.GAS throat carriage is an important public health issue, as the infection often leads to post streptococcal sequel and individuals colonized with GAS can serve as a source of spread of infections to other individuals in the community. An overall $4 \%$ of asymptomatic school children, irrespective of the sex and age groups $(P>0.05)$, were found to be colonized with GAS (Table 7). Due to unavailability of published literature on GAS carriage from Nepal, it is difficult to estimate the increasing or decreasing trend of the condition.

The present study showed that the prevalence of GAS among school aged children was $5.4 \%$ (Table 5). This finding is concurrent with other studies carried by Gurung et al.in $2010^{11}$ while is contradictory to studies conducted by Bista et al. in $2007^{12}$ Shrestha et al in $2001^{4}$ Rijal et al in $2009^{13}$ which showed the prevalence of GAS being $18 \%, 58.8 \%$, and $9.2 \%$ respectively. These variations may be because of differences in geographical location, settings and countries.

In general, the prevalence of carriage of GAS in healthy individuals decreases with age. In a report, the prevalence of streptococci group A was $6 \%$ in all the age groups studied, with $8.6 \%$ in carriers among healthy children and $12.2 \%$ on school children. Another study reports low prevalence of GAS in healthy individuals before the age of 3 years and in adults above 16 years. But on the contrary, the same study reports highest prevalence rate of GAS in the age group 3-15 years. In similar studies conducted in turkey, the rate of GAS carriage in asymptomatic school children varied from 2 to $46 \%$. In the present study, though statistically not significant, the age sub-group 9-12 years was the most susceptible group for throat carriage of GAS, followed by age subgroups 5-8 and 13-15 years. Age sub-group wise difference was not significant in our study since we had a narrow age range and focused only in children population from $5-15$ years of age. Few studies ${ }^{10}$ have reported the age group variation, which could be due to analysis of all age groups including adults. We found no significant variation of carriage rate with different schools as well.

A study carried out in Turkish school children showed the variation in the carriage rate of GAS in two different schools children; the overall carriage rate was $17 \%$, with $6 \%$ in students from school in impoverished area and $28 \%$ in students from school in suburban area. No significant variation with schools in our study could be due to the reason that all schools were almost similar in every aspect. Moreover, the schools included in this study were not geographically diverse and hence a similar rate was observed.

A study on environmental health effects of brick kilns in Kathmandu valley showed high prevalence of tonsillitis (4.17\%) and acute pharyngitis (4.08\%) in school children residing nearby brick kilns. We assume that air pollution may enhance the infection in GAS colonized children.
However, confirmatory relation can only be established when both epidemiological and etiological investigations are conducted to show if air pollution enhances GAS related throat infection in children.

Our study showed a quite high resistance rate $(71.0 \%)$ towards co-trimoxazole(Table 9,10$)$ which is one of the commonly used drugs to treat children infected with various diseases in Nepal. Such a high level of resistance with commonly used drug possesses a potential risk for spread of resistance to other microorganisms as well. In our study none of the strains, we isolated was found resistant with Penicillin, Ampicillin and Ciprofloxacin (Table 9,10). Penicillin and its derivative remained the drug of choice for streptococcal pharyngitis with stable minimum inhibitory concentration (MIC) during the last 70 years. However, reports of a rising MIC or diminished susceptibility to Penicillin have been published in recent years. ${ }^{14}$

Macrolide resistant S. pyogenes isolates are increasing in some parts of the world and $20-30 \%$ resistance is being reported in some countries. ${ }^{15}$ In the present study, $25 \%$ of S. pyogenes were resistant to Erythromycin while all of them were susceptible to Azithromycin. Now-a-days, because of its effectiveness and short course therapy, Azithromycin is commonly prescribed drug in Nepal for respiratory tract infections. However, its high frequency of prescription and possible irrational use may help to evolve Azithromycin resistant strain in the future. Therefore, before changing the therapeutic options, it is highly recommended to review the existing antimicrobials and their regimen based on their potency to save the valuable drugs for critical clinical conditions.

In this study other than BHS, Staphylococcus auerus was isolated from $48(9.26 \%)$ the swab sample (Table 3$)$. Bista et al. in $2005^{12}$ in comparative study of core and surface culture of tonsillectomy cases done in T.U.T.H. reported Staphylococcus aureus in $21 \%$ of cases. According to Longanathan et al in $2006^{16} \mathrm{~S}$. aureus was reported in $45.5 \%$ of cases and was the most common organism in adults with sore throat followed by K. pneumonia in $26.0 \%$ of cases and was the second most common organism. The low prevalence of these organisms in present study is may be due to pharyngeal swab culture do not reliably reflect presence of pathogen in tonsilar core as shown in study carried out by Alroosan et al. in $2008 .^{17}$

A similar kind of study conducted by different authors from various part of Nepal have shown prevalence of Staphylococcus aureus ranging from $15.4 \%{ }^{18}$ to $26.14 \%,{ }^{19}$ which is in accordance with the reports by Udaya et $\mathrm{al}^{20}$ (20\%) and Mehta et $\mathrm{al}^{21}$ (32.8\%) from India,Pakistan (39\% to $50 \%)$. ${ }^{22,23}$ However, it is slightly lower than the rate of $15.4 \%$ and $20 \%$ in two different studies conducted in Nepal. ${ }^{18,24}$

In this study it was observed that the sensitive drugs for GAS were Penicillin and their deravatives (100\%), Ciproflocaxin (100\%) and Azithromycin (100\%) followed by Erythromycin (75\%) and Cotrimoxazole (71.4\%) (Table 9,10). The result of sensitivity pattern of macrolide used in present study correlates with previous studies. ${ }^{11,13,25}$ 
The present study showed that Penicillin and its derivatives should be used to treat a case of GAS pharyngitis and Azithromycin for those who are allergic to Penicillin. The present study also showed that Staphylococcus aureus as an equally important agent of pharyngitis and hence throat swab culture should be requested for appropriate therapy.

\section{CONCLUSION}

The present preliminary study provides the base-line information on the GAS carriage rate and resistance trend among healthy school children. The percentage of GAS as well as $S$. aureus isolates was found high in male as compared to female. A high level of resistance with commonly used drug possesses a potential risk for spread of resistance to other microorganisms as well. In this study none of the strains isolated was found resistant with Penicillin, Ampicillin and Ciprofloxacin. Penicillin and its derivative remained the drug of choice for streptococcal pharyngitis with stable minimum inhibitory concentration (MIC) during the last 70 years. GAS throat carriage is an important public health issue, as the infection often leads to post streptococcal sequel and individuals colonized with GAS can serve as a source of spread of infections to other individuals in the community. The present study showed that Penicillin and its derivatives should be used to treat a case of GAS pharyngitis and Azithromycin for those who are allergic to Penicillin. The present study also showed that Staphylococcus aureus as an equally important agent of pharyngitis and hence throat swab culture should be requested for appropriate therapy.

Ethical approval: This research was approved by the Nepal health research council (NHRC) Kathmandu, Nepal. Letter of approval (Ref.No, 2237, 02 July 2015, Reg. No, 77/2015) was obtained after submitting the proposal to the committee.
Consent: Informed consent was taken from the patients before participating in the study. Data regarding personal information were kept confidential.

\section{RECOMMENDATIONS}

1. Study for larger sample from different places and age group are to be made.

2. Further studies should include development of methods to determine the prevalence of streptococcal infection.

3. Asymptomatic cases also showed culture positivity so frequent health check up is necessary for the children

4. Study of this type should be carried out across the country. Both symptomatic and asymptomatic cases should be detected.

\section{LIMITATION}

1. The duration of the study is short.

2. This study was done in only one district.

\section{ACKNOWLEDGEMENTS}

We would like to express our sincere thanks to the Department of Microbiology of Noble Medical College, Biratnagar and Sunsari Technical College, Dharan. This study would have never been possible without co-operation of the patients. My sincere thanks to Mr. Hemanta Khanal and Mr. Ganesh Kumar Singh for guiding me in data collection.

\section{CONFLICT OF INTREST \\ None}

\section{FINANCIAL DISCLOSURE}

None

7. Selwyn BJ. The epidemiology of acute respiratory tract infection in young children: comparison of findings from several developing countries. Reviews of infectious diseases. 1990 Nov 1;12 (Supplement_8): S870-88. PMID: 2270410 DOI: 10.1093/clinids/12. supplement_s870

8. WHO. Health Situation in South-East Asia Region. New Delhi: World Health Organization; 2002. DOI: 10.3126/njog.v7i1.8825.

9. Nair H, Nokes DJ, Gessner BD, Dherani M, Madhi SA, Singleton RJ, O'Brien KL, Roca A, Wright PF, Bruce N, Chandran A. Global burden of acute lower respiratory infections due to respiratory syncytial virus in young children: a systematic review and meta-analysis. The Lancet. 2010 May 7;375(9725):1545-55. DOI: 10.1016/S0140-6736(10)60206-1

10. Carapetis JR, Steer AC, Mulholland EK, Weber M. The global burden of group A streptococcal diseases. The Lancet infectious diseases. 2005 Nov 30;5(11):685-94. DOI: 10.1016/S1473-3099(05)70267-X

11. Gurung R, Budhathoki S, Amatya R, Poudyal N, Shrestha S, Baral R. Group A $\beta$-Haemolytic Streptococcus Infection Presenting with Sore Throat at Paediatric OPD. Health Renaissance. 2010;8(2):90-2. DOI: 10.3126/hren.v8i2.4418

12. Bista M, Sinha BK, Amatya RC, Tuladhar NR, Pokharel BM. Comparison of core and surface cultures in recurrent tonsillitis. Journal of Institute of Medicine. 2007 Jan 22;27(3):60-5. DOI: 10.3126/joim.v27i3.421 
13. Rijal KR, Dhakal N, Shah RC, Timilsina S, Mahato P, Thapa S, Ghimire P. Antibiotic susceptibility of Group A Streptococcus isolated from throat swab culture of school children in Pokhara, Nepal. Nepal Med Coll J. 2009 Dec;11(4):238-40. PMID: 20635601

14. Gunnarsson RK, Holm SE, Söderström M. The prevalence of betahaemolytic streptococci in throat specimens from healthy children and adults: implications for the clinical value of throat cultures. Scandinavian journal of primary health care. 1997 Jan 1;15(3):14955. DOI: 10.3109/02813439709018506

15. Cantón R, Loza E, Morosini MI, Baquero F. Antimicrobial resistance amongst isolates of Streptococcus pyogenes and Staphylococcus aureus in the PROTEKT antimicrobial surveillance programme during 1999-2000. Journal of Antimicrobial Chemotherapy. 2002 Sep 1;50(suppl_2):9-24. DOI: 10.1093/jac/dkf811

16. Loganathan A, Arumainathan UD, Raman R. Comparative study of bacteriology in recurrent tonsillitis among children and adults. Singapore medical journal. 2006 Apr;47(4):271-5. PMID: 16572236

17. Al-Roosan M, Al-Khtoum N, Al-Said H. Correlation between surface swab culture and tonsillar core culture in patients with recurrent tonsillitis. Khartoum Medical Journal. 2012 Feb 2;1(3):129-32.

18. Subedi S, Brahmadathan KN. Antimicrobial susceptibility patterns of clinical isolates of Staphylococcus aureus in Nepal. Clinical microbiology and infection. 2005 Mar 1;11(3):235-7. PMID: 15715723 DOI: 10.1111/j.1469-0691.2004.01056.x

19. Kumari N, Mohapatra TM, Singh YI. Prevalence of Methicillinresistant Staphylococcus aureus (MRSA) in a Tertiary-Care Hospital in Eastern Nepal;47:53-6. DOI: 10.31729/jnma.309
20. Shankar CU, Harish BN, Kumar PU, Navaneeth BV. Prevalence of methicillin resistant Staphylococcus aureus in JIPMER Hospital-a preliminary report. Indian Journal of Medical Microbiology. $1997 \mathrm{Jul}$ 1;15(3):137

21. Mehta AP, Rodrigues $C$, Sheth $K$, Jani S, Hakimiyan A, Fazalbhoy N. Control of methicillin resistant Staphylococcus aureus in a tertiary care centre: A five year study. Indian Journal of Medical Microbiology. $1998 \operatorname{Jan} 1 ; 16(1): 31$.

22. Butt T, Ahmad RN, Usman M, Mahmood A. Methicillin-resistant Staphylococcus aureus, Pakistan, 1996-2003. Emerging infectious diseases. 2004 Sep;10(9):1691. DOI: 10.3201/eid1009.030844

23. Farzana K, Hameed A. Resistance pattern of clinical isolates of Staphylococcus aureus against five groups of antibiotics. J Res Sci. 2006;17:19-26. PMID: 16380353

24. Baral R, Khanal B, Acharya A. Antimicrobial susceptibility patterns of clinical isolates of Staphylococcus aureus in Eastern Nepal. Health Renaissance. 2011;9(2):78-82. DOI: 10.1111/j.1469-0691.2004. 01056.x

25. Dumre SP, Sapkota K, Adhikari M, Acharya D, Karki M, Bista S, Basnyat $\mathrm{SR}$, Joshi SK. Asymptomatic throat carriage rate and antimicrobial resistance pattern of Streptococcus pyogenes in Nepalese school children. Kathmandu University Medical Journal. 2009;7(4):392-6. DOI: $10.3126 /$ kumj.v7i4.2760 